\title{
Effect of elevated temperatures on alkali-activated tungsten mining waste based materials
}

\author{
Rafael Silva-Figueiredo ${ }^{1, *}$ and João Castro-Gomes ${ }^{1}$ \\ ${ }^{1}$ Center of Materials and Building Technologies (C-MADE), Department of Civil Engineering and Architecture, University of Beira \\ Interior (UBI), 6201-001 Covilhã, Portugal
}

\begin{abstract}
Generally, alkali-activated materials (aka geopolymers) present good behaviour at high temperatures, but previous studies of geopolymers under elevated temperatures are, in most cases, focused on metakaolin or fly ash based geopolymers, making the information on geopolymers with mining waste mud almost inexistent. In this paper, were analysed geopolymers with different combinations of mining waste mud, waste glass powder, metakaolin and expanded cork in a total of 15 different mixtures using sodium hydroxide and sodium silicate as alkaline activators. Materials particle size used is under $500 \mu \mathrm{m}$ for mining waste mud, waste glass powder. Some mixtures also included expanded granulated cork with particle size between 2 to $4 \mathrm{~mm}$. Ten samples with $40 \times 40 \times 40 \mathrm{~mm}$ dimensions were used for the compression test, one sample for the TGA test, and one cube $(100 \times 100 \times 60 \mathrm{~mm})$ with a frustoconical hole (50 mm deep) and a $100 \times 100 \times 25 \mathrm{~mm}$ cover, for the cup test. All the mixtures were cured for $24 \mathrm{~h}$ at a temperature of $60{ }^{\circ} \mathrm{C}$ before being demoulded, and left at room temperature until they reach 7 days to be tested. On the 7th day, of each mixture, samples were placed in a static furnace before the compression test submitted to a temperature of $800{ }^{\circ} \mathrm{C}$ during $2 \mathrm{~h}$. Then, the compression test was performed and the values before and after exposure to high temperatures were compared. Were recorded maximum gains of $724 \%$ and maximum losses of $100 \%$ in the compressive strength. This preliminary result shows the potentials of mining waste alkali-activated materials for elevated temperatures applications.
\end{abstract}

\section{Introdution}

Since several years that we have been looking for viable alternatives to ordinary Portland cement (OPC), because its production is one of the main responsible for the emission of gaseous pollutants into the atmosphere, in this case $\mathrm{CO}_{2}$ (about $969 \mathrm{~kg}$ for each ton of clinker produced). According to Davidovits [1], geopolymers have very interesting characteristics (mechanical, chemical and durability) for construction and can be OPC alternative materials. In this work, we intend to demonstrate the potential of alkali activated tungsten mining waste based materials (AATMWM) when exposed to high temperatures and to compare with OPC. For this, several mixtures with different percentages of tungsten mining waste were tested for compression before and after being exposed to high temperatures, and were recorded the mass losses of each mixture by thermogravimetric analysis. Finally, the behaviour of each mixture was analysed for chemical resistance using $\mathrm{K}_{2} \mathrm{CO}_{3}$ as the attacking agent.

\section{Materials and methods}

\subsection{Materials characterization}

In the base mix, were used mining waste mud as a precursor, in this case mining waste mud (MD) from Panasqueira Mines, because they are rich in aluminosilicates. It was also used waste glass powder (GL) and metakaolin (MK), as precursors, to increase alkaline activation especially by adding $\mathrm{SiO}_{2}$ since the MD is mainly composed of muscovite and quartz which have a low reactivity even after calcination (Pacheco, Torgal 2008c). The fineness of the MD and GL used were less than $500 \mu \mathrm{m}$. The chemical composition of the precursors was determined by $\mathrm{x}$-ray (XRF) as indicated in table 1. Grain cork was added to the mixtures as lightweight aggregate.

Table 1 - Chemical composition of precursors

\begin{tabular}{|c|c|c|c|}
\hline \multirow{2}{*}{$\begin{array}{l}\text { Chemical } \\
\text { components }\end{array}$} & \multicolumn{3}{|c|}{ Constituants (\%) } \\
\hline & $\begin{array}{l}\text { waste } \\
\text { mud }\end{array}$ & Glass powder & Metakaolin \\
\hline $\mathrm{SiO}_{2}$ & 46,67 & 68,13 & 52,28 \\
\hline $\mathrm{Al}_{2} \mathrm{O}_{3}$ & 17,01 & 2,8 & 42,99 \\
\hline $\mathrm{K}_{2} \mathrm{O}$ & 4,9 & 0,86 & 0,94 \\
\hline $\mathrm{Na} 2 \mathrm{O}$ & 0,85 & 12,52 & 0,32 \\
\hline $\mathrm{CaO}$ & 0,69 & 10,52 & - \\
\hline $\mathrm{SO}_{3}$ & 7,9 & 0,23 & - \\
\hline $\mathrm{Fe}_{2} \mathrm{O}_{3}$ & 15,47 & 2,9 & 1,49 \\
\hline $\mathrm{MgO}$ & 4,83 & 2,04 & 0,47 \\
\hline
\end{tabular}

As alkaline activators were used sodium silicate $\left(\mathrm{Na}_{2} \mathrm{SiO}_{3}\right)$ and sodium hydroxide $(\mathrm{NaOH})$ whose chemical composition is presented in table 2. It was

\footnotetext{
* Corresponding author: rehnheta@gmail.com
} 
supplied by José Manuel Gomes dos Santos, Ltd. And LUXCITANIA, Ltd, respectively.

Table 2 - Chemical composition of activators

\begin{tabular}{|c|c|c|}
\hline \multirow{2}{*}{$\begin{array}{l}\text { Chemical } \\
\text { components }\end{array}$} & \multicolumn{2}{|c|}{ Constituants (g) } \\
\hline & $\begin{array}{l}\text { Sodium } \\
\text { silicate }\end{array}$ & $\begin{array}{c}\text { Sodium } \\
\text { hydroxide }\end{array}$ \\
\hline $\mathrm{Na}_{2} \mathrm{O}$ & 19,37 & 13,02 \\
\hline $\mathrm{SiO}_{2}$ & 62,6 & 0 \\
\hline $\mathrm{Al}_{2} \mathrm{O}_{3}$ & 0,9 & 0 \\
\hline $\mathrm{H}_{2} \mathrm{O}$ & 142,32 & 43,27 \\
\hline $\mathrm{K}_{2} \mathrm{O}$ & - & - \\
\hline $\mathrm{CaO}$ & - & - \\
\hline
\end{tabular}

\subsection{Mixtures}

In this study, a total of 15 different mixtures were prepared (Table 3) where the precursor / activator ratio of 2.85 was always used except for mixtures MK20JN and 27JN055 where this ratio was 1.1 and 2.17, respectively.

Table 3 - Mixtures composition
5 minutes using a magnetic mixer. The precursors were combined with the activators using an electric mixer at an average speed for approximately 2 to 3 minutes and about 1 minute at full speed.

\subsection{Curing regime and elevated temperature exposure}

The specimens were cured for 24 hours at a controlled temperature of approximately $60{ }^{\circ} \mathrm{C}$, then removed from respective moulds, then allowed to cool to room temperature until tested.

For the elevated temperature exposure was used a static furnace (muffle) with a maximum temperature of $1100^{\circ} \mathrm{C}$. The specimens were subjected to temperatures up to $800^{\circ} \mathrm{C}$, with an increase of $3.4^{\circ} \mathrm{C} / \mathrm{min}$, for 2 hours. After completion of the 2 hours' cycle, the specimens had a natural cooling inside the muffle until they reached $100^{\circ} \mathrm{C}$ at which time they were withdrawn and placed at room temperature until tested.

\begin{tabular}{|c|c|c|c|c|c|c|}
\hline \multirow[b]{2}{*}{ Mixture } & \multirow[b]{2}{*}{$\begin{array}{c}\text { Mining waste } \\
\text { mud }\end{array}$} & \multicolumn{2}{|c|}{ Precursors (g) } & \multicolumn{2}{|c|}{ Activators (g) } & \multirow{2}{*}{$\begin{array}{c}\text { Aggregates (g) } \\
\text { Cork } \\
\text { (granulated } \\
\text { expanded) }\end{array}$} \\
\hline & & $\begin{array}{c}\text { Glass } \\
\text { powder }\end{array}$ & Metakaolin & $\begin{array}{l}\text { Sodium } \\
\text { silicate }\end{array}$ & $\begin{array}{c}\text { Sodium } \\
\text { hydroxide }\end{array}$ & \\
\hline MD16JN & 4437,85 & - & - & 1167,86 & 389,29 & - \\
\hline MK20JN & - & - & 2278,03 & 1553,20 & 517,73 & - \\
\hline 20JN811 & 2144,69 & 219,09 & 227,80 & 682,00 & 227,33 & - \\
\hline GL21JN & - & 2190,93 & - & 576,56 & 192,19 & - \\
\hline $22 \mathrm{JN} 820$ & 2309,66 & 471,89 & - & 731,99 & 244,00 & - \\
\hline 22JN802 & 2309,66 & - & 490,65 & 736,93 & 245,64 & - \\
\hline $23 J N 52525$ & 1391,99 & 568,80 & 591,41 & 671,63 & 223,88 & - \\
\hline $23 \mathrm{JN} 811 \mathrm{C} 1$ & 2004,46 & 204,77 & 212,91 & 637,40 & 212,47 & 11,34 \\
\hline 27JN055 & - & 1137,60 & 1182,83 & 812,33 & 255,93 & - \\
\hline 29JN552718 & 1497,16 & 600,65 & 416,35 & 661,62 & 220,54 & - \\
\hline 30JN552718C1 & 1347,44 & 540,59 & 374,72 & 595,46 & 198,49 & 11,09 \\
\hline 4JL811C2 & 1742,15 & 177,97 & 185,05 & 553,99 & 184,66 & 22,18 \\
\hline 5JL622 & 1633,26 & 444,93 & 462,62 & 668,63 & 222,88 & - \\
\hline 6JL552718C2 & 1197,73 & 480,52 & 333,08 & 529,30 & 176,43 & 22,18 \\
\hline 11JL622C1 & 1469,94 & 400,44 & 416,35 & 601,77 & 200,59 & 11,09 \\
\hline
\end{tabular}

\subsection{Mixtures preparation}

Initially, the precursors were mixed, manually and dry, together with the aggregates until a uniform mixture was obtained. The activators were then blended, in this case sodium silicate and sodium hydroxide, for approximately 


\subsection{Compressive strength}

For the analysis of compressive strength were used a hydraulic press ELE $3000 \mathrm{kN}$ and testing was according to EN $1015-11$ for $40 \times 40 \times 40 \mathrm{~mm}$ cubic specimens. This equipment is provided y DECA-UBI in the construction laboratory.

\subsection{Thermogravimetric analysis}

To analyse the mass losses of the test specimens when exposed to high temperatures, the thermogravimetric test was used with the TGA Q50 equipment, available at the DECA-UBI materials laboratory, where the same 15 mixtures were analysed.

\subsection{Cup test}

In this test were made specimens with dimensions of 100 x $100 \times 60 \mathrm{~mm}$ with a small hole of $40 \mathrm{~mm}$ at the base and $50 \mathrm{~mm}$ at the surface of the mould and still others with dimensions of $100 \times 100 \times 25 \mathrm{~mm}$, with the mixtures indicated in section 2.2. Following the curing, as indicated in point 2.4, and following an ASTM C454, with some changes, was placed a mixture of $\mathrm{K}_{2} \mathrm{CO}_{3}$ (potassium carbonate) granulated on the hole of the sample. The hole is checked with the $100 \times 100 \times 25 \mathrm{~mm}$ sample and use a refractory mass to make a connection between test pieces. Hardened mortars were left to cure for 24 hours at a temperature of $60^{\circ} \mathrm{C}$ and only then was the specimen placed in the muffle at a temperature of up to $800^{\circ} \mathrm{C}$ with a temperature rise of $200^{\circ} \mathrm{C} / \mathrm{h}$ for 5 hours. At the end of the 5 hours cycle the specimens had a natural cooling inside the muffle up to $100^{\circ} \mathrm{C}$ at which time they were withdrawn and placed at room temperature until they were cut to see what changes have been caused by the presence of $\mathrm{K}_{2} \mathrm{CO}_{3}$.

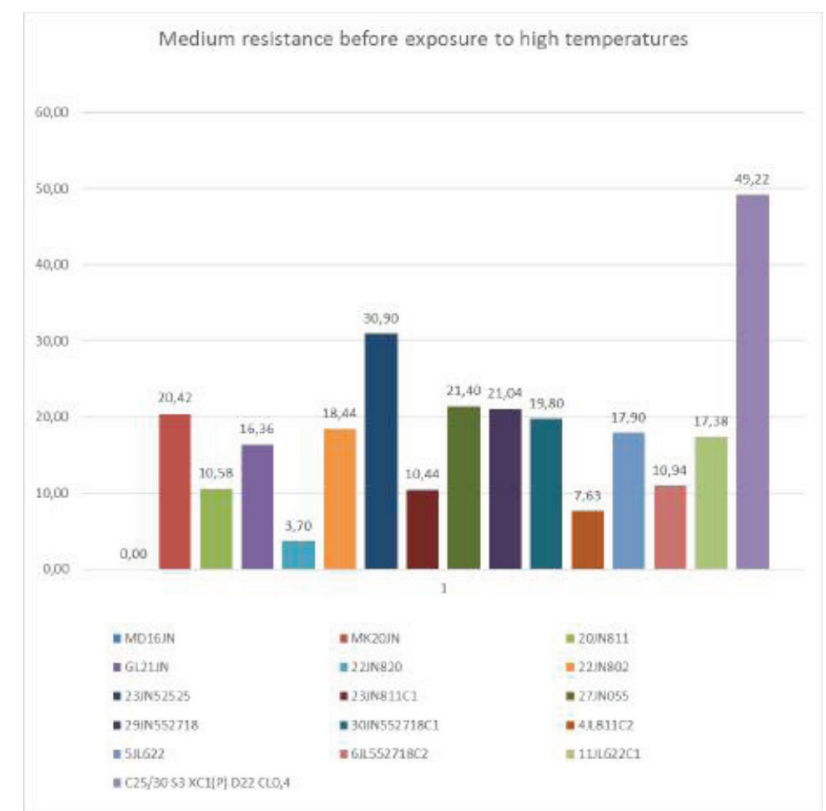

Graphic 1 - Compressive strength results before the exposure to high temperatures

\section{Results and discussions}

\subsection{Compressive strength}

The graphics 1 and 2 show the results obtained for each mixture before and after being exposed to high temperatures. Observing the results, we see that the highest resistance before being exposed was $30,9 \mathrm{MPa}$ in the 23JN52525 specimen and the highest resistance after being exposed to high temperatures was $41,5 \mathrm{MPa}$ in the 6JL52718C2 specimen. As can be observed, there was a great increase in compressive strength in all the mixtures, except for the mixtures MK20JN, GL21JN and 23JN52525 where a resistance loss of 13\%, 100\% and $16 \%$ was resisted respectively. But it should be noted that the greater increase was observed in the 22JN820 blend with an increase of $724 \%$.

\subsection{Thermogravimetric analysis}

Table 4 shows the results of mass losses of all mixtures and the mass loss of the precursors, except for the glass mixture for which was not possible to measure the mass loss since there was a risk of damaging the equipment when the glass enters in fusion. The average mass loss is of the order of $8.98 \%$, with the largest recorded loss of $13.67 \%$ in the MK20JN mixture and the lowest recorded loss of $1.76 \%$ in the metakaolin mixture.

\subsection{Cup test}

In this test, the analysis that was done was a visual observation of the damages caused by the presence of $\mathrm{K}_{2} \mathrm{CO}_{3}$ as can be observed in fig. 1 .

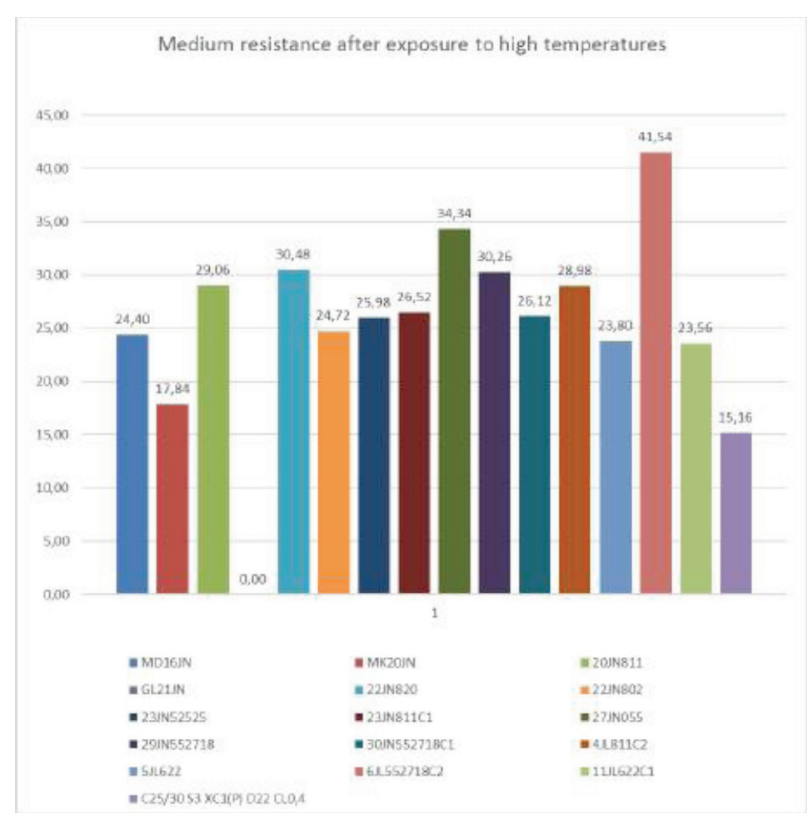

Graphic 2 - Compressive strength results after the exposure to high temperatures

The presence of $\mathrm{K}_{2} \mathrm{CO}_{3}$ had a significant impact on the internal degradation of the specimens. There was a very 
visible carbonation in the zone in direct contact with the chemical that caused the slit openings in all the specimens due to the expansion effect caused by the carbonation process.

Table 4 - TGA results

\begin{tabular}{cc}
\hline Mixture & Weigth loss (\%) \\
\hline Mud & 5,73 \\
Metakaolin & 1,76 \\
MD16JN & 7,99 \\
MK20JN & 13,67 \\
20JN811 & 11,08 \\
GL21JN & 7,45 \\
22JN820 & 8,71 \\
22JN802 & 8,82 \\
23JN52525 & 8,67 \\
23JN811C1 & 8,69 \\
27JN055 & 10,03 \\
29JN552718 & 10,92 \\
30JN552718C1 & 10,68 \\
4JL811C2 & 8,86 \\
5JL622 & 9,93 \\
6JL552718C2 & 11,07 \\
11JL622C1 & 8,59 \\
C25/30 & 9,60 \\
\hline
\end{tabular}

\section{Conclusion}

1- The results of the resistance test show that AATMWM has an excellent performance when exposed to high temperatures and compared with OPC, whose resistance after exposure to high temperatures had a decrease of $69 \%$, are a very viable solution. On the other hand, the excessive presence of $\mathrm{MK}$ in the mixtures proved to be detrimental to the resistance after exposure to high temperatures. The cork, as a light aggregate, proved to be beneficial, helping to increase the resistance of the mixtures after exposure to high temperatures.

2- The TGA results showed that the mass losses in the AATMWM are very similar in all mixtures and even the OPC shows a mass loss within the expected values. On the other hand, the mixture of metakaolin $(\mathrm{MK} 20 \mathrm{JN})$, which showed the greatest loss of mass $(13.67 \%)$, again demonstrated the weaknesses of the excessive use of metakaolin in the mixtures. According to previous [2] research, the increased moisture loss of the metakaolin-based mixtures causes damage to the internal matrix of the mixtures consequently a lower strength.

3- The cup test showed some AATMWM weaknesses for chemical attacks causing a visible internal and external degradation. Once again, the mixtures with more metakaolin were those that presented greater degradation.

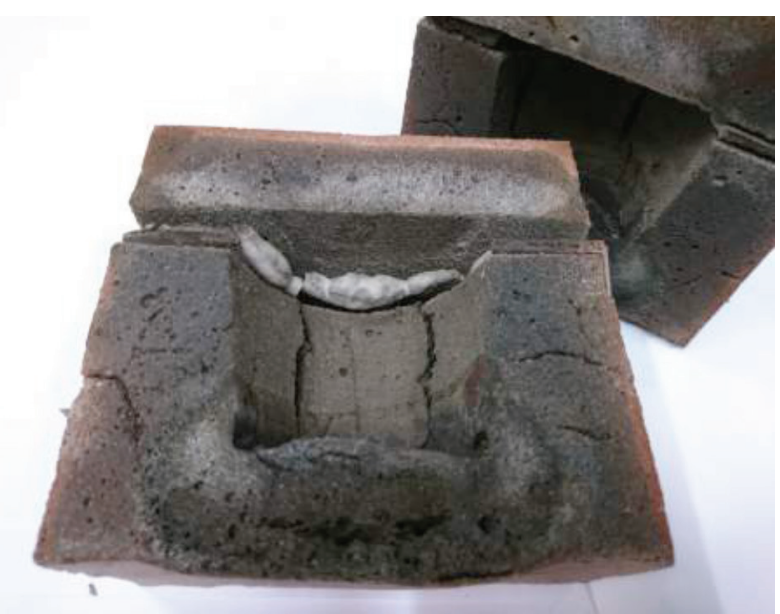

Figure 1 - Cup test sample after testing

\section{References}

[1] J. Davidovits, "Geopolymers: inorganic polymeric new materials," J Therm Anal, 1991.

[2] D. L. Y. Kong, J. G. Sanjayan, and K. Sagoecrentsil, "Comparative performance of geopolymers made with metakaolin and fly ash after exposure to elevated temperatures," vol. 37, pp. 1583-1589, 2007.

[3] D. L. Y. Kong and J. G. Sanjayan, "Cement and Concrete Research Effect of elevated temperatures on geopolymer paste , mortar and concrete," Cem. Concr. Res., vol. 40, no. 2, pp. 334-339, 2010.

[4] P. D. Æ. A. Ferna and G. C. L. Æ. A. P. Æ. J. S. J. Van Deventer, "Geopolymer technology : the current state of the art," no. 4, pp. 2917-2933, 2007. 